\title{
Diagrams for Navya-Nyāya
}

\author{
Jim Burton ${ }^{1}$ (D)
}

Published online: 31 January 2020

(C) The Author(s) 2020

\begin{abstract}
Although a number of authors have used diagrams extensively in their studies of Navya-Nyāya, they have done so to explain and illustrate concepts, not with the goal of reasoning with the diagrams themselves. Adherents of diagrammatic reasoning have made claims for its potential by pointing to key structural correspondences between diagrams and logical concepts, arguably lacking in sentential representations, and describing these relations using concepts such as "well matchedness" and "iconicity". A canonical example of this iconicity is the use of Euler diagrams to depict categorical syllogisms. Since the meaning of expressions in Indian logic differs in so many important ways from logic in the Western tradition, the use or adaptation of diagrams developed in the latter would seem to preclude iconicity. Thus, the development of diagrams which reflect the nature of inference in Navya-Nyāya, which centres on the anumāna inference schema, is motivated. In this paper we extend Ganeri's method of depicting the Vaiśeșika ontology with graphs to include syntax intended to expose the nature of anumanna. The diagrams are given a formal basis: i.e. abstract syntax, inference rules defined abstractly and a graph-theoretic semantics. These are the first formalised logical diagrams that aim to reflect the nature of the anumāna inference. This paper lays the way for further work in extending the formalism to cover more of Navya-Nyāya, and in exploring a dialogue between properties of the formalism and of Navya-Nyāya.
\end{abstract}

Keywords Indian logic $\cdot$ Navya-Nyāya $\cdot$ Logical diagrams

Jim Burton

j.burton@brighton.ac.uk

1 Centre for Secure, Intelligent and Usable Systems, School of Computing, Engineering and Mathematics, University of Brighton, Brighton BN2 4GJ, UK 


\section{Introduction}

Although none of the original Sanskrit authors whose work makes up the logicophilosophical tradition of Navya-Nyāya used diagrams, modern authors have used a variety of graphical notations to explain and illustrate the system. The author recently surveyed these notations (Burton et al. 2018) (in collaboration with Choudhury and Chakraborty), analysing the notations' fitness-for-purpose according to two main criteria: these were Charles Peirce's categorisation of signs (Short 2009) (primarily, the concept of iconicity) and Cheng's cognitive framework on the effectiveness of diagrams (Cheng 2016). In that study we explained our view that the use of spatial diagrams (Euler, Venn, linear diagrams etc), as some authors have done (e.g. Chi 1990), is poorly matched to the meaning of Navya-Nyāya. Such notations excel at representing syllogistic reasoning and were, to one degree or another, developed with that process in mind. However, in ways that we explore below, reasoning with anumāna is not syllogistic reasoning, justifying the search for a more appropriate notation.

As a first step towards designing diagrams which are well matched to the meaning of Navya-Nyāya, we begin by considering the structure of meaning in that system. The semantics of Navya-Nyāya means that intension, i.e. individuals and their properties, is of the first importance. In fact it may be no more correct to call Navya-Nyāya intensional than it is to call it extensional, as it has features that exhibit each perspective; an example of an extensional concept is anugama (Guha 2016, p. 209). What matters when constructing a sign which is iconic for reasoning, which is what we will attempt to do, is to reveal the relationships that are essential to inference. Rather than spatial notations designed to show the subsumption, intersection or disjointness of concepts, diagrams based on various kinds of network are more appropriate. Most diagrams found in the secondary Navya-Nyāya literature are, in fact, topological notations based on networks; examples include the diagrams of Wada (2007), Das (2006) and Ganeri (2001b). Each author had their own (frequently overlapping) purposes in mind when developing their notations, such as the depiction of vyāpti (Das) or ontology (Ganeri). Naturally, the success of the results should be considered in light of their particular contexts. None of the notations, however, was developed for use as a diagrammatic logic, i.e. for reasoning by manipulation of the diagram and its parts in ways that correspond to the process of inference in Navya-Nyāya. The absence of diagrammatic inference rules is not the only obstacle; concepts which are key to visualising Nyāyan inference are missing. This includes notation to represent the likeness and unlikeness classes which justify the use of examples. Furthermore, although the mapping between a diagram and its underlying meaning may be more or less clear (Das, for instance, provides an algorithm for reading his diagrams that can be used to reconstruct the corresponding expression), each of the notations is explained informally. Just as Euler diagrams can be said to possess the same relations as the antecedents of a syllogistic argument, supporting inference by revealing that style of reasoning "as it really is", we seek to do the same for anumāna. This position is explained further in "Source notations" section. 
It should be noted that, despite having the invaluable assistance of several Sanskrit scholars thanked at the end of the article, this work is based on the author's understanding of secondary texts. Principal among these are Guha's textbook Navya-Nyāya System of Logic Guha (2016) and Ganeri's Philosophy in Classical India Ganeri (2001b), which provides inspiration for the diagrams. There is no one "official" version of this philosophy, which developed over many centuries in a process of disputation, clarification and detailed refinement. For our current purpose, we leave Nyaya's historical development to one side and take definitions and concepts from Guha's work op cit unless noted otherwise.

In the next section we establish some basic terms and concepts of Navya-Nyāya. We then describe the source notations from which our diagrams take inspiration ("Source notations" section), followed by the description of the diagrams themselves, which we call anumāna diagrams. We do this by first giving an overview of the drawn diagrams ("Anumāna diagrams with sapakșa only" section), then via the definition of their abstract syntax ("Abstract syntax" section) and semantics ("Semantics" section). We do this for the simplest case of anumāna in which only a positive corroborating example is provided, and then consider the case when a counterexample is also given. In this latter case, we demonstrate the drawn diagrams and, to avoid repetition, give a sketch of the extension to the formalism. We conclude with a look ahead to future work, including extending the diagrams to accommodate a larger fragment of Navya-Nyāya.

\section{The basic terms and concepts of Navya-Nyāya}

We will only attempt to describe those aspects of Navya-Nyāya that are needed in order to understand the diagrams in later sections. Broader and more detailed introductions can be found in, for instance, Ganeri (2001) and Guha (2016).

Navya-Nyāya, like all philosophical logic, is concerned with the analysis of thought and the justification of reasoning. Unlike logics in the Western tradition, it combines techniques of rhetoric (how to construct a convincing argument), epistemology (the analysis of truth and knowledge) and logic proper (how to draw valid conclusions on the basis of existing evidence). Nyāya (in its original and "new" forms) is closely linked with the Vaiśeșika school, from which it takes their seven-part ontology wholesale. The Vaiśeșika ontology divides objects in the real world into seven types. A positive entity is either a universal, a quality, a motion, or a substance (which may be compound or atomic) or an individuator Ganeri (2001b). The types are distinguished from each other by inherence (samāvaya): the number of entities each type inheres in and the number which may inhere in it. Nothing may inhere in a universal, while universals inhere in qualities. For example, the universal blueness inheres in a quality, blue, which is a particular shade of the colour. Qualities inhere in substances; a particular shade of blue may inhere in a pot, for example. A pot is a compound substance composed of smaller parts. The pot inheres in each of those parts, all the way down to the atomic substances it is made of, which inhere in nothing. The other type of entity which inheres in atomic substances is the individuator, which allows us to distinguish one atom from another. The 
seventh type of entity is the negative entity of absence (abhāva). Since the Nyayāikas believe that every cognition has some content, when we perceive the absence of a pot on the ground, that absence is an entity with real existence. What we perceive in this case is an abhāva which is counter-positive (pratiyogi) to potness (the quality of being a pot) and which has an absential-spatial location in the ground. This is an example of relational absence, and there are other varieties dealing with temporal absence and inequality. Nothing inheres in a negative entity. As we will see in the "Source notations" section, this model of reality is reflected to a greater or lesser degree in the diagrams used to visualise Navya-Nyāya.

The usual introduction to Navya-Nyāya is via the anumāna, or inferential schema. There are two varieties, with three and five steps respectively. The example below is the five part variety, or pararthanumāna, with the wording taken from Ingalls (1955):

\section{Anumāna 1}

1. Thesis: Word is non-eternal.

2. Reason: Because it possesses the property of being produced.

3. Statement of pervasion and example(s): What possesses the property of being produced is seen to be non-eternal, as a pot. What possesses the property of not being produced is seen to be eternal, as the soul.

4. Application: It (word) is like this (i.e. possesses the property of being produced).

5. Conclusion: Therefore word is non-eternal.

When this logical structure was introduced to the West in 1824 by Colebrooke it was named the "Indian syllogism". This choice of name formed part of the misunderstanding of Indian logic in the West that was to last the best part of a century. Compared to Aristotle's syllogistic, pararthanumāna may seem to be inadequate in several respects: particularly, its repetition (steps 1 and 5) and the redundant and distracting appeal to examples in step 3. The history of these misunderstandings is described by Ganeri (2001a).

In fact, pararthanumāna bears no real resemblance to syllogistic reasoning. It is not concerned with classes of things, relations between classes or membership of those classes. Its content concerns individuals, their pervasion by properties and an inference that can be made thereby. Mullick explains that the distinction between implication and entailment is key to (mis)understanding the nature of inference in pararthanumāna, which should be seen as an inference schema or rule rather than a series of propositions. Implication "holds by virtue of the meaning-content of propositions rather than their truth-values, [and] this must itself be because of the concepts they contain." Mullick described the inference taking place in pararthanumāna as "conceptual implication". Furthermore, pararthanumāna is a schema because although each example discusses particular objects (words, hillsides and so on) the role of these "paradigmatic" objects is as placeholders for any objects or properties that stand in the given relations to each other (Mullick 1976). 
Two of the key notions at work in anumāna are locus and locatee. In the example above, the loci are word (which is the pakșa, or locus that we want to reach a conclusion about), pot (the sapaksa, or example which is claimed to be like the pakșa) and soul (the vipakșa, the example which is claimed to be unlike the pakșa) (Guha 2016, p. 35). The locatees are the properties of being eternal, of being produced, and the absence of each of those properties. Non-eternal-ness is the sädhya, the target property or thing we want to prove is true of the pakșa.

The treatment of relation is strongly intensional. The eternal-ness of an entity such as a soul is conceived of as a quality which inheres in a locus. The quality is thus delimited by and particular to the locus (through a process called avacchedakatva, the delimitor/delimited relation) (Guha 2016, p. 17). The eternalness of a given soul is not universal eternal-ness, and is not equivalent to the eternalness of a separate entity. This approach extends to every cognition. To express the notion "a pot is on the ground" the Nyayāikas construct a statement equivalent to "contact delimited by pot-ness inheres in the ground". This approach was developed to avoid the ambiguity of ordinary speech.

One of the most distinctive features of Navya-Nyāya is the treatment of absence $(a b h \bar{a} v a)$ and negation. Recalling the example of our perception of the absence of a pot on the ground, that absence is an entity with real existence. In this case, "absence delimited by pot-ness inheres in the ground". Returning to the pararthanumāna example above, for word to be non-eternal means that the absence of eternal-ness is located in word; this absence is also located in pot but is not located in soul (Guha 2016, pp. 76-99). Our second example of pararthanumāna, which we will use to explain the third step and use of examples, is the most commonly cited:

\section{Anumāna 2}

1. Thesis: This hill is fiery.

2. Reason: Because it is smoky.

3. Statement of pervasion and example(s): What possesses the property of being smoky is also fiery, as in the kitchen hearth. What possesses the property of not being smoky is not fiery, as in the lake.

4. Application: This hill is so.

5. Conclusion: Therefore this hill is fiery.

Step 3, the statement of pervasion and example(s), has been taken by various authors as equivalent to a predicate logic expression such as $\forall x . S(x) \rightarrow F(x)$. This fails to reflect the intended meaning in several ways. Apart from $S(x)$ and $F(x)$ being an inadequate way to represent the notions of locus, locatee and avacchedaka, this is a statement about pervasion, as the name suggests. Entities which are pervaded by smoke are necessarily pervaded by fire. This is about the relation between the sädhya (target) and hetu (reason) properties. For the hetu to be a reliable reason property, the sādhya must be seen wherever the hetu is seen. It is quite possible that the sādhya is seen in some instances where the hetu is not; a red-hot iron is said by the Nyayāikas to possess fire but not smoke (Ganeri (2001b), p. 90). But it must 
certainly be true that the extent of the hetu is strictly contained within that of the sādhya. This leads to the Buddhist logician Dinnāga's "reason with three characteristics" (Ganeri 2001b, p. 115):

[A proper reason must be] present in the site of inference and what is like it and absent in what is not.

How do we know the examples are well-chosen, and what is "like" and "unlike" the site of inference? How do we know that there are no counterexamples yet to be observed (a Black Swan event)? As pointed out by Dinnāga, we are concerned here with like and unlike in respect to the sädhya, not the hetu. In commentary on Dinnāga's work, Dharmakirti went on to claim that there are three ways in which hetu and sädhya may be linked: both properties may be linked to (possibly caused by) the same phenomenon, may be linked by metaphysical causation, or we may reach a conclusion about their interdependence based on the lack of counterexamples. After observing some small number of examples we can be satisfied, and stop looking. (Ganeri 2001b, p. 121) The reliance on the examples in pararthanumana can be problematic for readers hoping to understand Navya-Nyāya, leading some to think that this is an informal case-based reasoning by analogy. However, if we accept the validity of the existence of likeness and unlikeness classes and accept the assumption that we are able to identify an example from each, then the status of pararthanumāna as a formal inference schema is clear. Matilal puts it thus (Matilal 1991, quoted in Sen and Chatterjee 2010):

In short, the Nyāya strategy is to appeal to our intuitions about knowledge, in order to learn something about reasoning and not vice versa.

In the next section we describe those diagrams used by modern authors which have inspired our own, and make some observations about their potential effectiveness for reasoning.

\section{Source notations}

The first source of inspiration for our diagrams are those that appear in Ramesh Chandra Das' translation of the classic nineteenth century primer, the NavyaNyāyabhasapradipa of Mahesa Chandra Nyāyaratna (Das 2006). To give a flavour of the notation, Fig. 1 shows Das' depiction of a mutual absence between "cloth" and "pot". These diagrams follow the node-link or network style employed earlier by Wada (2001), but have a richer syntax that allows more kinds of information to be expressed. Rectangles represent elements of a cognition (alternatively, ontological entities) and downward arrows represent the inherence relation (samavāya). Solid arrows which are not vertically oriented represent other relations and can be labelled to indicate the relation in question. Arrows with a double edge ( $\Rightarrow$ and $\Leftrightarrow$ ) represent the uni- and bidirectional determinor relations (nirupya/nirupita and nirupya/nirupaka). The "harpoon" (৬) shows that one thing is counterpositive to another and an arrow with a dashed edge indicates the denial of a relation. An important innovation enables the reconstruction of a Navya-Nyāya expression from 


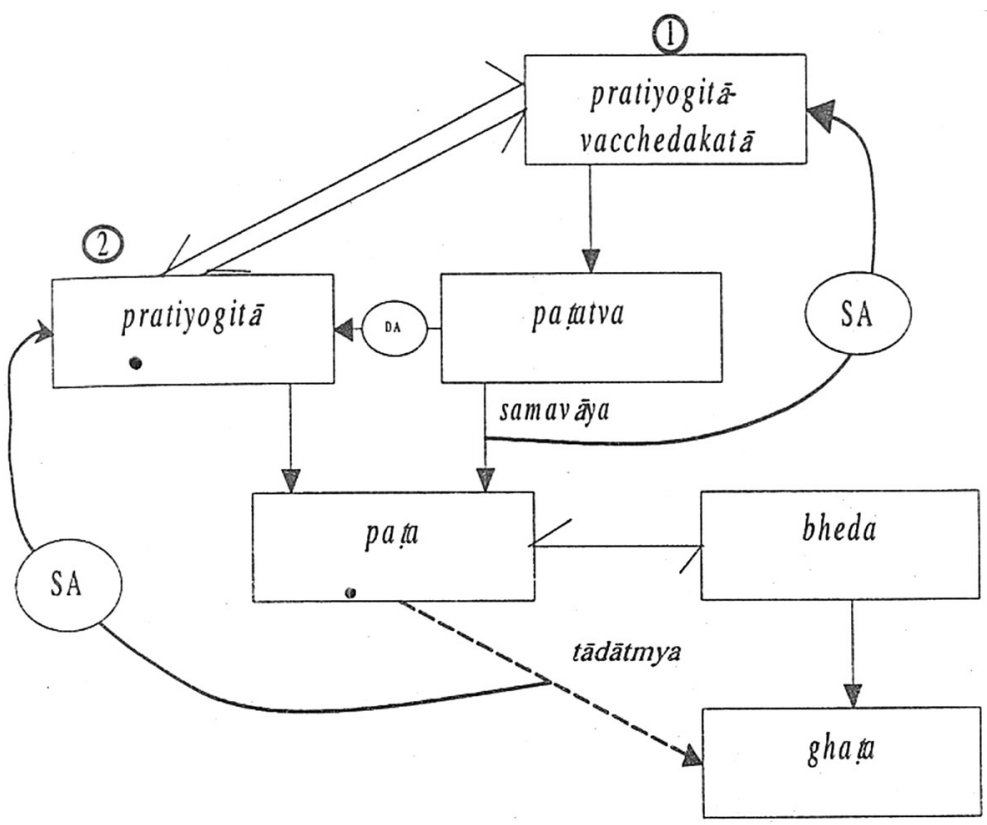

Fig. 1 The diagrams of Ramesh Chandra Das (2006)

the diagram; this relies on the addition of the meta-diagrammatic feature of a numbered circle to label contextual properties (Das refers to it as "an artificial device"). Contextual properties are those that determine other entities, i.e. those which are adjuncts in the nirüpakatva relation. The order in which contextual properties are introduced affects the meaning of the expression, similar to the order of quantifiers in sentential logic. The numbered circles in Das' diagrams that label contextual properties are to be read in order, producing the desired meaning.

The vocabulary of Das' diagrams is given in Fig. 2. As stated above, orientation has semantic importance. A set of nodes and edges arranged horizontally has a different meaning to the same nodes and edges in a vertical arrangement. In Fig. 3, because the nodes in the cognition on the left are arranged vertically, we read the arrow as the locus/locatee ( $\bar{a}$ dheya/ädhära) or property/posessor (dharma/dharmin) relation. In the right-hand cognition, the arrow could be any relation and (in the absence of a label) all we know is that $X$ is related to $Y$.

The analysis of Das' diagrams in Burton et al. (2018) notes that they are richly expressive (e.g., as compared to those of Wada) and precise (thanks to the numbering device). However, several areas for improvement can be found. The commitment to completeness means that the diagrams are prone to clutter and may tend to obscure the key aspects of inference, something which we discuss further below. Assigning meaning to orientation is an arbitrary convention that places unnecessary limits on the ways in which diagrams can be constructed. Finally, the diagrams contain elements that do not relate to any real entity, i.e. to any component of the corresponding Navya-Nyāya expression. The numbered labels fall into this 
Fig. 2 The syntax of Das' diagrams

Fig. 3 The semantics of orientation in Das' diagrams
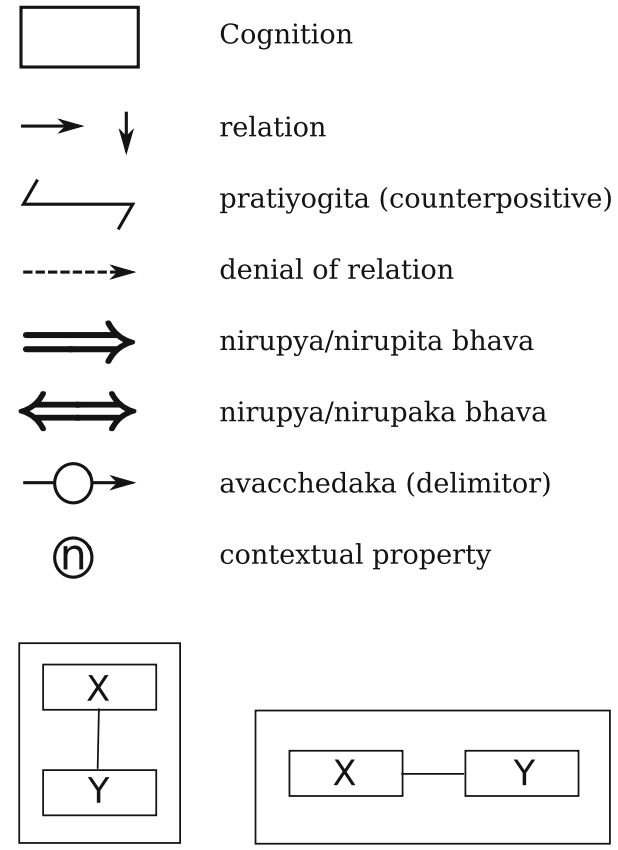

category but, as discussed, certainly perform an important function and are justified by the requirement of an unambiguous reading order. The treatment of abhāva is more questionable - this is done using a dashed line to deny the existence of a relation between two entities. In Fig. 1 the dashed line denies the identity (tâdātmya) relation between pata (pot) and gata (ground). There is no entity forming part of the underlying meaning to which the dashed line relates.

In his 2001 book Philosophy in Classical India (Ganeri 2001b), Ganeri uses graphs to illustrate the structure and relations of the Vaiśeșika ontology. The style of the diagrams arises from the observation that Udayana's justification of the ontology differentiates between entities on the basis of inherence, and that these differences can be seen as properties of a directed graph. Each natural kind in the ontology is uniquely determined by the number of entities it can inhere in, and the number of entities that can inhere in it. Thus, what distinguishes a universal, from the graph-theoretic point of view, is that it is a node with incoming valency of 0 , since a universal is that in which nothing inheres, and so on for the other kinds.

Each type of node described so far is a bhāva (positive entity) and an arrow sourced on node $a$ and targeting node $b$ means that $a$ inheres in $b$. Figure 4 shows an ontology in which a universal inheres in two qualities; these inhere in a compound and atomic substance respectively, and so on. ${ }^{1}$

To represent abhāva a new type of node and two new edges are introduced. The $\Longrightarrow$ edge denotes counterpositiveness (pratiyogita) while the heavy edge is the

\footnotetext{
1 It should be noted that although the graphs adopt the perspective of depicting the inherence relation by edges, inherence is itself a positive entity not fundamentally different to the entities depicted by nodes.
} 
Fig. 4 An ontology in Ganeri's graphs

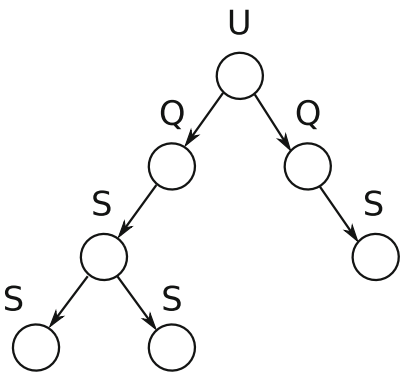

Fig. 5 Abhāva in Ganeri's graphs

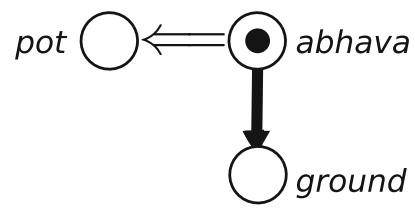

absential-spatial relation abhāvīya-svarūpa sambhanda. In this way, no non-existent "denial of relation" is required and, relative to Das, a more authentic state of affairs is depicted (Fig. 5).

The two notations we have considered each take different approaches to depicting cognition. Das' diagrams are designed with vyāpti in mind, and aim for comprehensiveness, containing everything we need to fully reconstruct a NavyaNyāya expression. Relative to Ganeri's graphs, they are rich and flexible: there are seven distinct types of edge and these may be attached to nodes or to other edges. It seems to us that this commitment to depict the complete structure of cognition may occlude the key aspects of inference (note that this is our priority, not that of Das). In Burton et al. (2018) we argued that this lack of perspicuity can cause the diagrams to perform quite poorly on several of Cheng's criteria for effective diagrammatic representation (Cheng 216). These criteria take the form of design goals, such as injunctions to use One token for each type and provide an Overarching interpretive scheme. With their rich syntax and unambiguous reading order, Das's diagrams meet these goals. However, our objections explained above relate to criteria such as Reflect the structure of concepts, Coherent encoding of primary concepts. From a Peircean perspective the sine qua non of logical diagrams is iconicity, most often glossed as the mode in which signs convey their meaning by resemblance. This description fails to convey the nuances of the concept however, which Peirce defined in several places in different ways. One such definition is that icons are signs from which we can "learn more", i.e. that provide more information than was required for their construction. Under this interpretation a sign resembles its object if and only if study of the sign can yield new information about the object (Hookway 2002). This is the case for using circles to depict a syllogism - the conclusion is necessarily contained in and revealed by the premises. A diagram is a special kind of icon whose parts stand in these relations to each other, and which comes with rules that allow us to manipulate the parts in reliably valid, illuminating ways. This aspect of iconicity is also captured under the name well-matchedness 
(Gurr 1999). A well-matched notation shares certain important characteristics with the domain it depicts. For instance, Euler diagrams are well-matched to propositions and assertions about sets because they have "the potential to directly capture pertinent aspects of the represented artifact" Gurr and Tourlas (2000). Ambrosio emphasises the active, contextual nature of iconicity: "Constructing' an icon amounts to discovering, and selecting, relevant respects in which a representation captures salient features of the object it stands for." (Ambrosio 2014). These will be our design goals in the next section, but for the time being we can safely focus on the structural correspondences between an iconic sign and its object; such a sign can be said to have the very relations it represents. Das' diagrams have certain iconic features: their node-link structure resembles the locus/locatee structure of a NavyaNyāya expression; a rectangle, $P$, connected to a second rectangle, $Q$, by a vertical arrow could be said to "resemble" two elements of cognition that are adjuncts in the inherence relation. However, although two graphical objects joined by an arrow may be said to resemble any pair of entities bound by a relation, there is nothing about verticality that resembles inherence. The convention of edge orientation is a symbolic feature (one which conveys meaning by habit, natural or acquired) and mitigates or even destroys any iconicity possessed by inherence edges.

Compared to the approach taken by Das, Ganeri's graphs are minimal, focusing solely on inherence and absence. They do this in an iconic way that corresponds ideally with the underlying meaning, in that the graphs have exactly the same structure as the fragment of cognition that is depicted. They are not expressive enough for our purpose, however. Consider the task of using Ganeri's graphs to depict (or carry out, taking Mullick's view of anumāna as a schema) the inference embodied in anumāna 2. Firstly, this inference depends not only on inherence but also contact (samyoga) between entities-smoke and fire are in contact with the hillside and kitchen (or, more properly, contact delimited by these qualities inheres in the loci). Suppose we introduce a new type of edge, $\rightarrow$ to denote contact. Then Fig. 6 applies the graphs to the inference. ${ }^{2}$

How can we formalise the application of step (3) to step (2), resulting in (4)? One of the things which is hard for many newcomers to understand about Navya-Nyāya is the status of the examples - what distinguishes Navya-Nyāya from informal reasoning by analogy? In what sense is this valid reasoning? Authors such as Schayer, Staal and others have characterised the third step in terms of predicate logic. For instance, Staal's occurrence relation, $A$, links together subject ( $p, p a k s a)$, probandum ( $s, s \bar{d}$ hhya) and evidence ( $h$, hetu): $A(h, p) \rightarrow A(s, p)$. (Staal 1973) Whatever the notation, in order to know that the example presented is a reliable one, we must consider Dinnāga's "statement with three characteristics". We need a diagrammatic indication that the hetu appears in the paksa (shown in step 2), always occurs in things which are like the paksa, and never occurs in those things which are

\footnotetext{
${ }^{2}$ We use the terms "smoke-ness" and "fire-ness" to refer to the universals corresponding to smoke and fire respectively, which should not be confused with the familiar terms "smokiness" and "fieriness". Smokiness is an attribute of the loci (mountain etc.) while smoke-ness is an attribute of smoke. In general, we add the suffix "-ness" to words to generate a level of abstraction, similarly to the application of the Sanskrit suffix "-tva". Thanks to Professor Prabal Sen and an anonymous reviewer for notes on terminology.
} 
Fig. 6 Inference in Ganeri's graphs

(1)

(2)
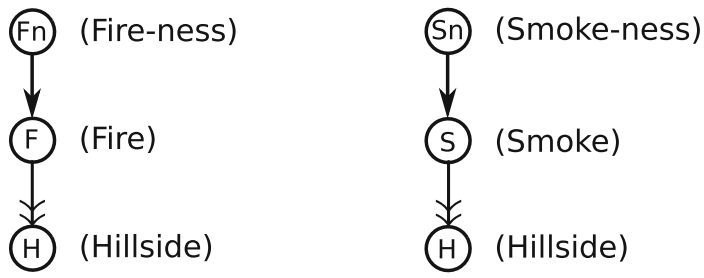

(3)

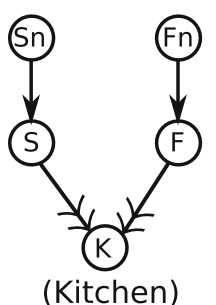

(4)

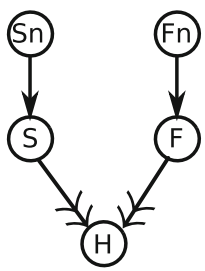

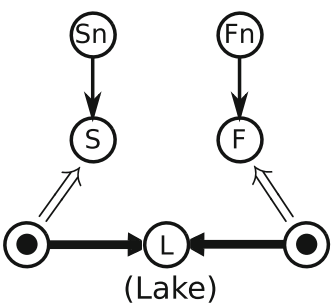

(5)

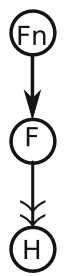

unlike the pakșa. But step (3) only shows that the second and third characteristics are true of the given examples. We need to know that the paksa and locus of the evidence (sapakșa) are in the same likeness class with regard to the target property, and conversely for the locus of the counterevidence (vipaksa). To be used in this context, Ganeri's graphs need to be extended since we have no way to describe these relationships.

Figure 7 shows how Das presents the same inference in a fully specified way. Through the reading technique, the result corresponds exactly with the intended meaning but, in our view, becomes cluttered and fails to shed light on the key aspects of the inference. It could be said that this clutter is not inherent to the notation, since any aspect of cognition which was not considered salient could be left out of the diagram. But in a notation which specialises in inference we think it desirable that diagrams raise the most salient concepts to the foreground. We take these key aspects of inference to include pervasion, the three characteristics and the presence of the likeness and unlikeness classes. Therefore, our approach to designing anumāna diagrams could be summarised as extending Ganeri's graphs with additions that expose the essence of anumanna and, in so doing, to take inspiration for those extensions from Das where possible. 


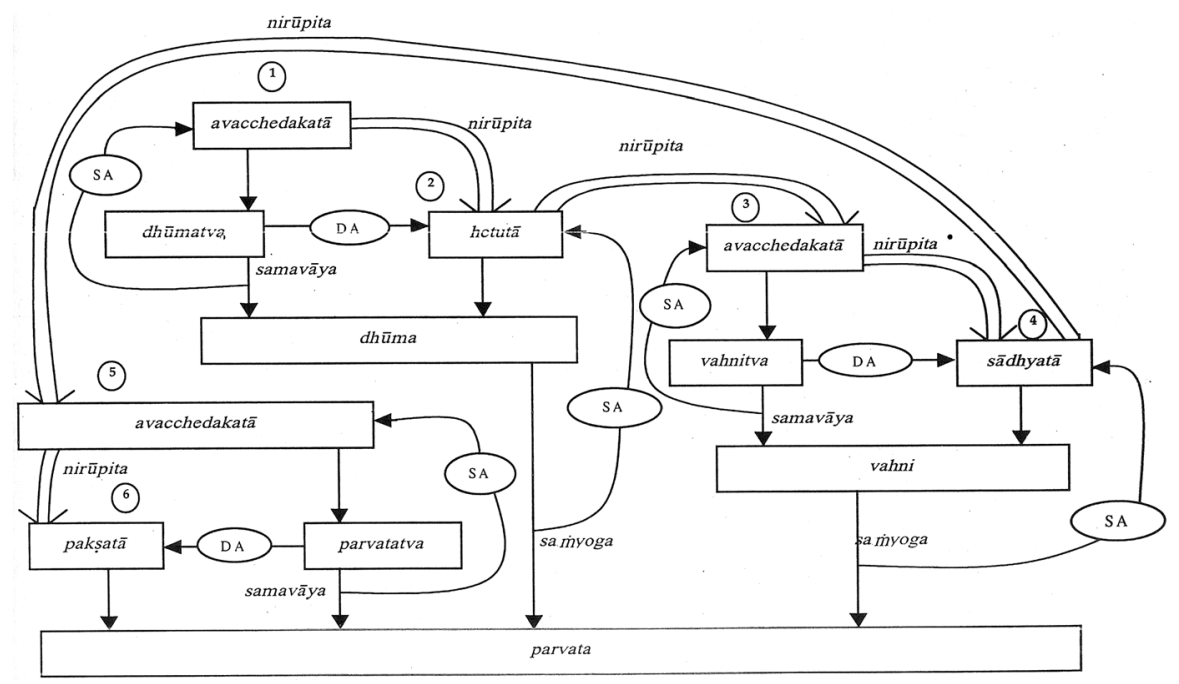

Fig. 7 Anumāna in Das' diagrams Das (2006)

\section{Anumāna diagrams with sapakṣa only}

We begin by considering the affirmative case in which only positive evidence is provided. Inferences may be made on the basis of contact (samyoga) or inherence (samavāya); our first example focuses on contact and uses the two-headed arrow, $\rightarrow$, for this purpose as before. Figure 8 shows the substances Smoke $(\mathrm{S})$ and Fire $(\mathrm{F})$ in contact with the Kitchen, labelled K. It also exposes the relevance of this information by indicating our knowledge of vyāpti and likeness. We use doubleheaded arrows $(\leftrightarrow)$ to denote joint membership of a likeness class $(\mathrm{K}$ and $\mathrm{H}$ are alike). We use an arrow sourced on a entity and targeting a likeness edge to show what kind of likeness is involved ( $\mathrm{K}$ and $\mathrm{H}$ are alike with respect to $\mathrm{F}$ ). We also need to depict the vyapti relation of pervasion between the substances, for which we use the $\Longrightarrow$ edge ( $S$ is pervaded by $F$ ). Note that this arrow is a shorthand device; it does not reflect the full structure of vyāpti, which depends on a more complex set of relations, but reduces a great deal of clutter and allows the diagrams to maintain their focus on anumāna. The result is that our diagrams are "high level", attempting to reduce complexity by creating diagrammatic syntax which denotes semantic entities with complex structure. The opposite approach is more common. For instance, Das has no special edge for vyäpti; one sambhanda edge is used for all relations and labelled accordingly). These choices relate to an ancient distinction in logical notation; those which reveal the essential or atomic structure of an expression and are thus well suited for analysis versus those, like ours, which capture higher level concepts and which are intended for use as a calculus.

Together with the hetu, which is unchanged from Fig. 6, Fig. 9 makes explicit the information we need to apply the anumanna schema. With the notation for contact and likeness in place we have the syntactic information to justify relying on the sapaksa as evidence and reaching the conclusion on its basis. Figure 10 shows the 
Fig. 8 Determining the likeness class

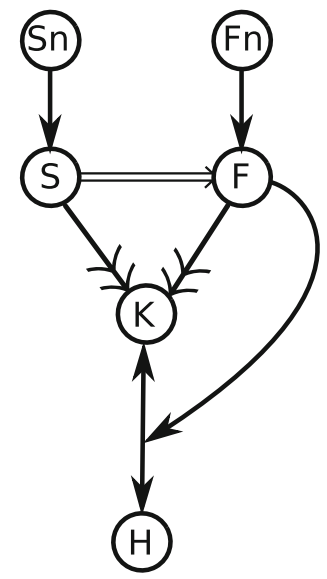

(1)



(3)

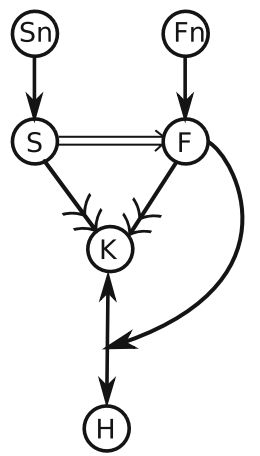

(2)

(sn)

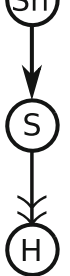

(4)

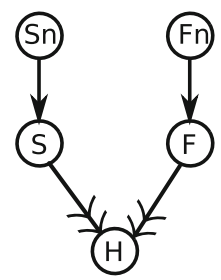

(5)

Fn

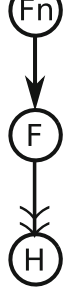

Fig. 9 Carrying out anumāna

inference in question, to be defined syntactically in the following section. Finally, to reach step (5), the conclusion, we need a rule that will allow us to detach nodes from the graph, as shown in Fig. 11. Next, we define anumāna diagrams at the abstract level. 


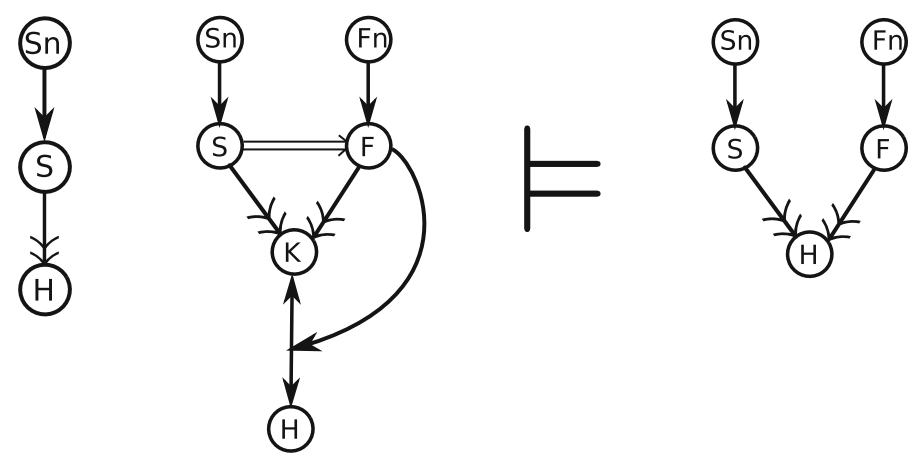

Fig. 10 Applying knowledge of vyāpti

Fig. 11 Detaching nodes
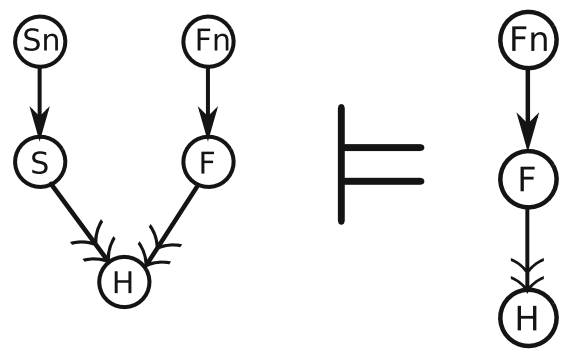

\section{Abstract syntax}

Informally, an abstract anumāna diagram is a graph with five types of edge. Edges indicating inherence, contact and the vyāpti relation are directed and between nodes. Edges indicating membership of a likeness class are undirected and between nodes. The last type of edge is sourced on nodes but targets other edges, indicating the (directed) relation that determines the identity of the likeness class. Using Fig. 12 as an example, this diagram will have the following abstract elements:

- A set of nodes, $B=\{a, b, c, d, e, f\}$.

- A set of inherence edges, $I=\{(a, b),(c, d)\}$.

- A set of contact edges, $C=\{(b, e),(d, e)\}$.

- A set of likeness edges, $L=\{(e, f)\}$.

- A set of vyāpti edges, $V=\{(a, c)\}$.

- A set of determinor edges, $N=(c,(e, f))$ (where $N$ stands for nirupaka, i.e. describer or determinor).

Then the diagram as a whole has the abstraction $D=(B, I, C, L, V, N)$. We assume the existence of a countable set of nodes, $\mathcal{N}$.

Definition 1 Anumāna diagram (sapakșa only). An anumāna diagram is a tuple $(B, I, C, L, V, N)$ where: 
Fig. 12 Abstract syntax of a diagram



$-B \subseteq \mathcal{N}$ is a set of nodes,

$-I, C, V \subseteq B \times B$ are sets of ordered pairs of nodes,

$-L \subseteq B \times B$ is a set of unordered pairs of nodes, and

$-N \subseteq B \times L$ is a set of ordered pairs of nodes and elements of $L$.

We next define functions that allow us to access nodes that represent entities with different natural kinds, based on their valencies and level within the graph.

Definition 2 Let $D=(B, I, C, L, V, N)$ be an anumāna diagram. Then we define the following functions:

- $\operatorname{univ}(D)=\{y \in B: \neg \exists x \in B((x, y) \in I)\}$ are the universal nodes of $D$,

- qual $(D)=\{y \in B: \exists(x, y) \in I(x \in \operatorname{univ}(D))\}$ are the quality nodes of $D$, and

- $\operatorname{subs}(D)=\{x \in B: l(x, D) \geq 2\}$ are the substance nodes of $D$, where $l(x, D)$ is the level or minimum distance of the node $x$ from a universal via inherence edges in $D$ as follows:

$$
l(x, D)=\min \left(\left\{\begin{array}{ll}
0 & \text { if }(y, x) \notin I \cup C, \\
\forall(y, x) \in I(1+l(y, D)) & \text { otherwise. }
\end{array}\right\}\right)
$$

Returning to the example in Fig. 12, univ $(D)=\{a, c\}, \operatorname{qual}(D)=\{b, d\}$ and $\operatorname{subs}(D)=\{e\}$. We now need to express several constraints on well-formedness, given in the next definition.

Definition 3 (Well-formedness) Let $D=(B, I, C, L, V, N)$ be an anumāna diagram where the following is true:

- the graph formed by the inherence, contact and likeness edges is connected:

$$
B=\{x:(x, y) \in I \cup C \cup L\},
$$


- $D$ contains universal nodes, quality nodes and substance nodes:

$$
\operatorname{univ}(D) \neq \emptyset \wedge \operatorname{qual}(D) \neq \emptyset \wedge \operatorname{subs}(D) \neq \emptyset,
$$

- likeness edges are between substance nodes:

$$
\forall(x, y) \in L(x, y \in \operatorname{subs}(D))
$$

- vyāpti edges are between quality nodes:

$$
\forall(x, y) \in V(x, y \in q u a l(D)) \text {, and }
$$

- determinor edges in are sourced on quality nodes and target likeness edges:

$$
\forall(x,(y, z)) \in N(x \in \operatorname{qual}(D) \wedge(y, z) \in L) .
$$

Then we write that $D$ is well-formed.

When we want to make a new graph by adding nodes to an existing one we assume that we can draw "fresh", i.e. heretofore unused, nodes from $\mathcal{N}$. Now we have enough tools to define inference rules representing the anumāna schema. The first rule carries out an affirmative inference in the case where contact is involved and only one example is provided. The identifiers used in the definition of the rule match those in the example given in Fig. 13, which can be used to help follow the definition.

Definition 4 Anumāna (affirmative, contact, sapakșa only). Let $D_{1}=\left(B_{1}, I_{1}, C_{1}\right.$, $\left.L_{1}, V_{1}, N_{1}\right)$ and $D_{2}=\left(B_{2}, I_{2}, C_{2}, L_{2}, V_{2}, N_{2}\right)$ be well-formed anumāna diagrams such that the following is true:

1. there are nodes $p \in \operatorname{subs}\left(D_{1}\right), h \in \operatorname{qual}\left(D_{1}\right)$ and $t \in \operatorname{univ}\left(D_{1}\right)$ which are connected as follows: $(t, h) \in I_{1}$ and $(h, p) \in C_{1}$,
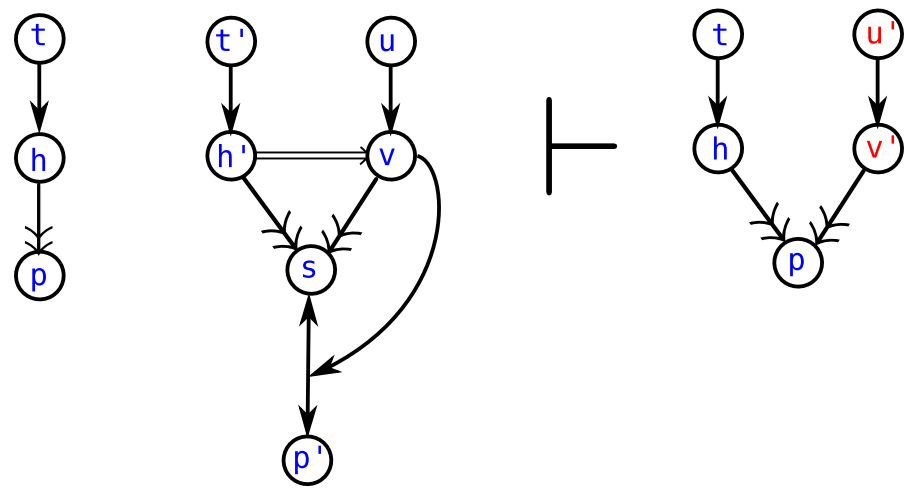

$$
D_{1}
$$

$D_{2}$

$D_{3}$

Fig. 13 Identifiers in the definition of the Anumāna rule 
2. there are nodes $s \in \operatorname{subs}\left(D_{2}\right), h^{\prime} \in \operatorname{qual}\left(D_{2}\right)$ and $t^{\prime} \in \operatorname{univ}\left(D_{2}\right)$ which are connected as follows: $\left(t^{\prime}, h^{\prime}\right) \in I_{2}$ and $\left(h^{\prime}, s\right) \in C_{2}$,

3. there is a node $p^{\prime} \in B_{2}$ such that $\left(s, p^{\prime}\right) \in L_{2}$,

4. there are nodes $u \in \operatorname{univ}\left(D_{2}\right)$ and $v \in \operatorname{qual}\left(D_{2}\right)$ with edges $(u, v) \in I_{2}$ and $(v, s) \in C_{2}$,

5. there is an edge $\left(h^{\prime}, v\right) \in V_{2}$, and

6. there is an edge $\left(v,\left(s, p^{\prime}\right)\right) \in N_{2}$.

Let $u^{\prime}$ and $v^{\prime}$ be two fresh nodes and let

- $B^{\prime}=B_{1} \cup\left\{u^{\prime}, v^{\prime}\right\}$,

$-I^{\prime}=I_{1} \cup\left\{\left(u^{\prime}, v^{\prime}\right)\right\}$,

- $C^{\prime}=C_{1} \cup\left\{\left(v^{\prime}, p\right)\right\}$ and

- $D_{3}=\left(B^{\prime}, I^{\prime}, C^{\prime}, L, V, N\right)$.

Then we can construct $D_{3}$ given $D_{1}$ and $D_{2}$, written $D_{1}, D_{2} \vdash D_{3}$.

Note that this rule will only work as intended when the pairs of nodes $t$ and $t^{\prime}$, $h$ and $h^{\prime}$ and $p$ and $p^{\prime}$ represent the same entities in the semantic domain. This is a semantic requirement that cannot be determined at the syntactic level, imposing a qualification on the soundness of the rule that will be discussed below. The next rule enables us to detach nodes. We can only do this when we are sure that the process will maintain well-formedness. We need to avoid the possibilities of leaving the graph unconnected or of containing a quality in which no universal inheres, for example. In Fig. 14, if we remove any node from $D_{1}$ then the result will not be a well-formed graph. From $D_{2}$, we can remove either $\mathrm{S}$ and $\mathrm{Sn}$, or $\mathrm{F}$ and Fn. Removing any other nodes would result in a badly formed graph.

Figure 15 shows an example of applying the rule; note that the node labels match the identifiers used in the definition.

Definition 5 (Inference rule: detach nodes) Let $D=(B, I, C, L, V, N)$ be an anumāna diagram such that the following is true:

1. there are nodes $t, u \in \operatorname{univ}(D), h, v \in q u a l(D)$ and $p \in \operatorname{subs}(D)$,

2. there are edges $(t, h)$ and $(u, v)$ in $I$, and

3. there are edges $(h, p)$ and $(v, p)$ in $C$.

Let the following be true:

$-B^{\prime}=B-\{u, v\}$,

Fig. 14 Constraints on detaching nodes
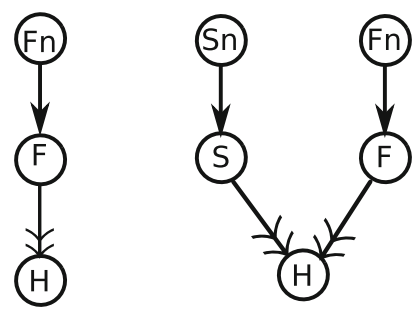

$D_{1}$

$D_{2}$ 
Fig. 15 Identifiers in the definition of the Detach nodes rule
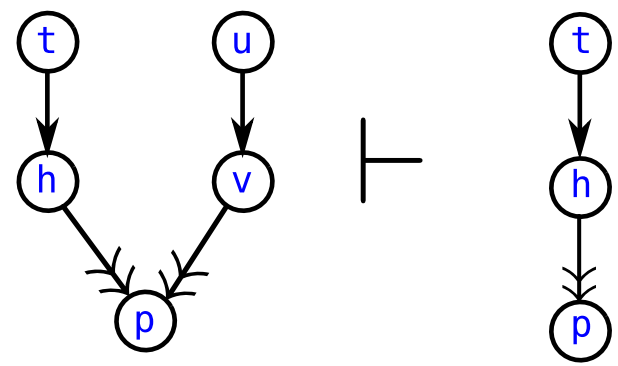

$-I^{\prime}=I-\{(u, v)\}$,

- $C^{\prime}=I-\{(v, p)\}$, and

- $D^{\prime}=\left(B^{\prime}, I^{\prime}, C^{\prime}, L, V, N\right)$.

Then we can construct $D^{\prime}$ from $D$, written $D \vdash D^{\prime}$.

In the following section we define the semantics of anumanna diagrams and a mapping between the abstract and semantic levels, before showing that our two rules are sound.

\section{Semantics}

In formalising the semantics of the diagrams we have been faced with a number of quite difficult choices. Firstly, we believe that to follow one of the traditional styles used to define the semantic level of formal logics would be to depart from NavyaNyāya's intended meaning in a way that undermines our project. It would not make sense, for example, to use the conventional model-theoretic semantics of predicate logic typically applied to Euler-based diagrams (e.g. Shin 1994) or Kripke models and tableaux methods of modal logics (Gasquet et al. 2014), even though the latter are graph-based. For the same reasons that we reject the use of spatial diagrams, we aim to look beyond these techniques of constructing and checking models to find methods that better reflect the true nature of a system which mixes logic and epistemology. The departures we will have to make from the techniques mentioned above are necessary because we are dealing with conceptual knowledge rather than truth-carrying relations. We are attempting to model a system in which intuition plays an important role and in which certain things may be said to be true for all time and have objective metaphysical existence.

We consider the existence and contents of likeness and unlikeness classes to be axiomatic, standing outside any interpretation of a diagram. For any property, $p \in \mathcal{U}$, where $\mathcal{U}$ is the universe of positive (bhāva) entities, we can identify the associated sets Like $(p): \mathbb{P U}$ and Unlike $(p): \mathbb{P U}$.

To say that a diagram is satisfiable means that it represents a possible cognition. That will be the case if the structure of the diagram reflects the valencies of the ontology and if the relations and membership of likeness and unlikeness classes depicted correspond with the real world. For convenience we require only that universals are not inhered in by any entity, disregarding the further stipulation that each universal is exemplified in at least two qualities. Because our diagrams do not 
depict individuators (entities in which nothing inheres but which inhere in exactly one atomic substance), this is enough to make the valency of universals unique. Our diagrams are fragments of cognition; as stated above, we make no attempt to show the Nyāyan view of cognition exhaustively.

An interpretation, $\mathcal{I}=(\cup$,$) , is a pair whose elements are a universe and a$ mapping between nodes and that set, $: \mathcal{N} \rightarrow U$. $\mathcal{U}$ is intended to denote the real universe so for any subset, $U \subseteq \mathcal{U}$, we may not presume that we know its full extent. For instance, consider the concept Dog within U, i.e. those compound substances in $U$ that meet some definition of the anugama class Dog. We can never know the extent of Dog, only its intent; those properties that must be possessed by its members, such being a mammal, having four legs and so on. In practice, we can only indicate the set by listing those entities which we know must be present in $U$. We will demonstrate these ideas reusing Fig. 12 and its abstraction as an example, and duplicate the diagram in Fig. 16 for convenience. Any interpretation for this diagram, $(\mathrm{U}$,$) , must meet the following requirements:$

- The universe must contain at least six elements, say

$$
\mathrm{U}=\{\text { Smoke, Smoke-ness, Fire, Fire-ness, Kitchen, Hearth, ... }\} .
$$

- These elements should have the right natural kinds: Smoke-ness and Fire-ness are universals, Smoke, Fire, Kitchen and Hearth are substances.

- The desired relations persist between the elements: Smoke-ness inheres in Smoke, which is in contact with Kitchen and so on for the other inherence and contact edges in the diagram. Smoke and Fire are adjuncts in the vyapti relation. Furthermore,

$$
\text { Kitchen, Hearth } \in \text { Like(Fire). }
$$

- The mapping, maps nodes to the appropriate entities: $=\{(a$, Smoke-ness $)$, $(b$, Smoke), ( $c$, Fire-ness), ( $d$, Fire), (e, Kitchen), $(f$, Hearth $)\}$.

Fig. 16 Semantics of a diagram

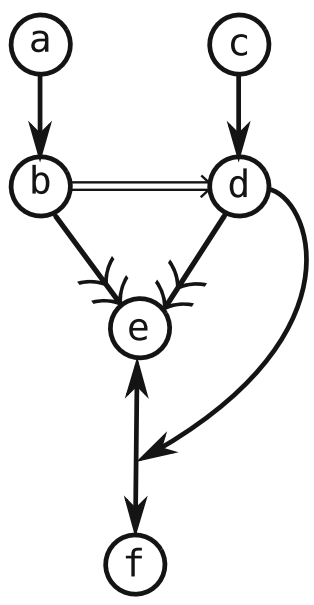


We next define three conditions that, we will go on to show, form the basis of satisfiability.

Definition 6 (Three conditions) Let $D=(B, I, C, L, V, N)$ be a well-formed anumāna diagram and $\mathcal{I}=(\mathrm{U}$,$) be an interpretation. Let \operatorname{inh}(\mathrm{U})$ and $\operatorname{con}(\mathrm{U})$ be the extents of the inherence and contact relations in $U$ and let $l(e, U)$ be the extension of the $l$ (level) function to the inherence relation at the semantic level. Let the following conditions be true:

1. Bhava condition Each node maps to a distinct entity in the interpretation. That is,

$$
\forall a, b \in B((a),(b) \in \mathrm{U} \wedge a \neq b \Rightarrow(a) \neq(b)) .
$$

2. Ontology condition maps the nodes in $\operatorname{univ}(D)$, qual $(D)$ and $\operatorname{subs}(D)$ to universals, qualities and substances in $U$, respectively. That is,

$$
\begin{aligned}
& \forall u \in \operatorname{univ}(D)(\neg \exists x \in \mathbf{U}((x,(u)) \in \operatorname{inh}(\mathrm{U}))), \\
& \forall q \in \operatorname{qual}(D) \quad(\exists u \in \mathrm{U}((u,(q)) \in \operatorname{inh}(\mathrm{U}) \\
& \wedge \neg \exists x \in \mathrm{U}((x, u) \in \operatorname{inh}(\mathrm{U}))) \\
& \wedge \neg \exists y \in \mathrm{U}((y,(q) \in \operatorname{inh}(\mathrm{U}) \wedge y \neq u))) \text {, and } \\
& s \in \operatorname{subs}(D) \Rightarrow l((s), \mathrm{U}) \geq 2 \text {. }
\end{aligned}
$$

3. Sambhanda condition For each edge between two nodes in $D$, the corresponding relation between entities exists:

(a) if $(a, b) \in I$ then $((a),(b)) \in \operatorname{inh}(U)$,

(b) if $(a, b) \in C$ then $((a),(b)) \in \operatorname{con}(U)$,

(c) if $(b, c) \in L$ then there is an edge $(a,(b, c)) \in P$ such that $(b),(c) \in \operatorname{Like}((a))$,

(d) if $(a, b) \in V$ then $(a)$ and $(b)$ are adjuncts in the vyāpti relation.

Theorem 1 (Satisfiability) Let $D=(B, I, C, L, V, N)$ be a well-formed anumāna diagram and $\mathcal{I}=(\mathrm{U}$,$) be an interpretation. \mathcal{I}$ is a model for $D$ if and only if the three conditions hold for $D$ with respect to $\mathcal{I}$.

Proof First we show that if the three conditions hold then $\mathcal{I}$ is a model. Since the Bhāva Condition holds then every node represents a real and distinct entity. That is, the following is true:

$$
(B)=\bigcup_{b \in B}(b) \subseteq U
$$

and no two nodes in the abstract diagram denote the same entity. The Ontology Condition means that nodes in the diagram map to entities of the corresponding natural kind and ensures that the diagram reflects the proper ontological structure. Since this condition holds then each $u \in \operatorname{univ}(D)$ maps to an entity in $U$ in which nothing inheres. Each $q \in \operatorname{qual}(D)$ maps to an entity in which one universal inheres and each $s \in \operatorname{subs}(D)$ maps to a substance, i.e. an entity in which only qualities inhere. 
The Sambhanda Condition means that each edge in $D$ denotes that the corresponding relation holds between the two corresponding entities in U. It also ensures that each pair of entities that the diagram depicts as belonging to a likeness class do indeed belong to that class. Thus, the diagram represents a viable cognition and $\mathcal{I}$ is a model for $D$.

For the other direction, assume that the Bhāva Condition does not hold and that there exists a $b \in B$ such that $(b) \notin U$. Then maps this node to an entity which does not exist in $U$ and $\mathcal{I}$ is not a model for $D$. Otherwise there exists a distinct pair of nodes $a, b \in B$ such that $(a)=(b)$, and is again inadequate.

Suppose that the Ontology Condition does not hold and so there is a node $u \in \operatorname{univ}(D)$ such that there exists an entity $x \in \mathrm{U}$ and $(x,(u)) \in \operatorname{inh}(\mathrm{U})$. Then $(u)$ is not a universal and $\mathcal{I}$ is not a model for $D$. Similarly for the other ontological types. If the Sambhanda Condition does not hold then it can be shown in a similar way that $\mathcal{I}$ is not a model for $D$. Therefore $\mathcal{I}$ is a model for $D$ if and only if the three conditions hold.

Theorem 2 Let $D=(B, I, C, L, V, N)$ be a well-formed anumāna diagram. Then there exists an interpretation $\mathcal{I}$, which is a model for $D$.

Proof (Sketch) By theorem 1, the theorem is true if we can construct an $\mathcal{I}$ such that the three conditions hold. We can see that it must always be possible to identify some $U \subseteq \mathcal{U}$ and construct a mapping, , so that the Bhāva Condition holds. Since $D$ is well-formed the edges in $D$ represent a possible cognition with respect to the Ontology and sambhanda conditions.

Next we give a sketch of the proof that our first inference rule is sound.

Theorem 3 Inference rule: Anumāna (affirmative, contact, sapakșa only) is sound Let $D_{1}, D_{2}$ and $D_{3}$ be anumāna diagrams so that $D_{1}, D_{2} \vdash D_{3}$ as per the definition of the rule. Furthermore, let $t, h$ and $p$, and $t^{\prime}, h^{\prime}$ and $p^{\prime}$ be nodes in $D_{1}$ and $D_{2}$ respectively as per the definition of the rule. Then any model for both $D_{1}$ and $D_{2}$ is a model for $D_{3}$ and the rule is valid, written $D_{1}, D_{2} \models D_{3}$, if and only if the pairs of nodes $t$ and $t^{\prime}, h$ and $h^{\prime}$ and $p$ and $p^{\prime}$ represent the same entities in the semantic domain.

Proof (Sketch) First we show that if the salient nodes in $D_{1}$ and $D_{2}$ do not represent the same entities in the semantic domain then the application of the rule is invalid. Let $\mathcal{I}=(\mathrm{U}$,$) be any interpretation. Assume that D_{1}$ and $D_{2}$ are well-formed. From $D_{2}$ we know that the quality $\left(h^{\prime}\right)$ pervades the quality $(v)$. However, if $h$ and $h^{\prime}$ do not represent the same entity, i.e. $(h) \neq\left(h^{\prime}\right)$, then we have no knowledge of any relation between $(h)$ and $(v)$ and any application of the rule is unsound. By the same reasoning, the application of the rule is unsound if $(t) \neq\left(t^{\prime}\right)$ or $(p) \neq\left(p^{\prime}\right)$.

For the other direction we need to start by showing that we can construct an interpretation which is a model for both $D_{1}$ and $D_{2}$. By theorem 2 we can construct an interpretation, $\mathcal{I}$, which models $D_{2}$. Then we can trivially extend $\mathcal{I}$ to reflect the information present in $D_{1}$. We know from the definition of the rule that the evidence of the property we wish to prove in $D_{1}$ exists in both $D_{1}$ and $D_{2}$. Also, we know that the relevant likeness class information is present in $D_{2} . D_{3}$ is a copy of $D_{1}$ to which two nodes, $u^{\prime}$ and $v^{\prime}$, have been added. We know that these nodes represent entities 
which are related to each other in the appropriate way since $\mathcal{I}$ is a model for $D_{2}$. Thus, the application of the rule is sound if the salient nodes in $D_{1}$ and $D_{2}$ represent the same entities in the semantic domain.

We omit the proof for the soundness of the second rule, which merely weakens information.

Theorem 4 Inference rule: detach nodes is sound. Let $D_{1}$ and $D_{2}$ be anumāna diagrams as per the definition of the rule. Then any model for $D_{1}$ is a model for $D_{2}$ and the rule is valid, written $D_{1} \vDash D_{2}$.

Next we consider the situation in which both positive and negative corroborating evidence is required.

\section{Anumāna with negation}

To depict a negated thesis (e.g. "word is not eternal") or a counterexample (e.g. "as not in the lake") we need a device to represent abhāva. We use Ganeri's notation for absential nodes (a circle with a filled circle inside it) and absential-spatial relations (a heavy black edge). Since Ganeri used the $\Longrightarrow$ edge to denote the counterpositive relation (already used by us to denote vyāpti), we make use of the harpoon edge $(\overrightarrow{)})$ that Das employed for this purpose. Figure 17 depicts double negation, where $\mathrm{Bn}$ represents blueness, $B$ represents a particular shade of blue and $P$ represents pot; the absence of the absence of blue is located in a blue pot (Guha 2016, p. 207).

Incorporating new notation to express unlikeness, Fig. 18 tells us that the absence of S (smoke) and the absence of F (fire) both inhere in L (the lake). The "broken" double-headed arrow denotes joint membership of an unlikeness class. So, Fig. 18 also asserts that $\mathrm{L}$ and $\mathrm{H}$ (the hillside) are joint members of the unlikeness class determined by the universal Fn, fire-ness.

We will need a new anumāna rule which can be applied when vipakșa is required, taking the form demonstrated in Fig. 19.

Our final example is another in which negation plays a prominent role. Not only are both sapakșa and vipakșa provided but the thesis/conclusion is negative. It differs from earlier examples in relying only on inherence and not contact. This is Anumāna 1 (see p. 3), having the thesis "Word is not eternal", given as a diagram in Fig. 20.

The extension of the formalism from the previous section to accommodate the inference in Fig. 20 is straightforward. The definition of abstract diagrams would

Fig. 17 Double negation

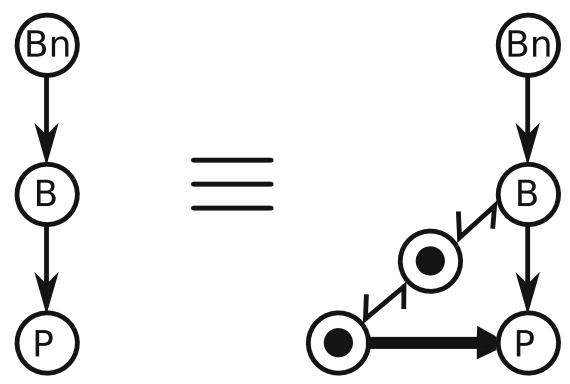


Fig. 18 Determining the unlikeness class
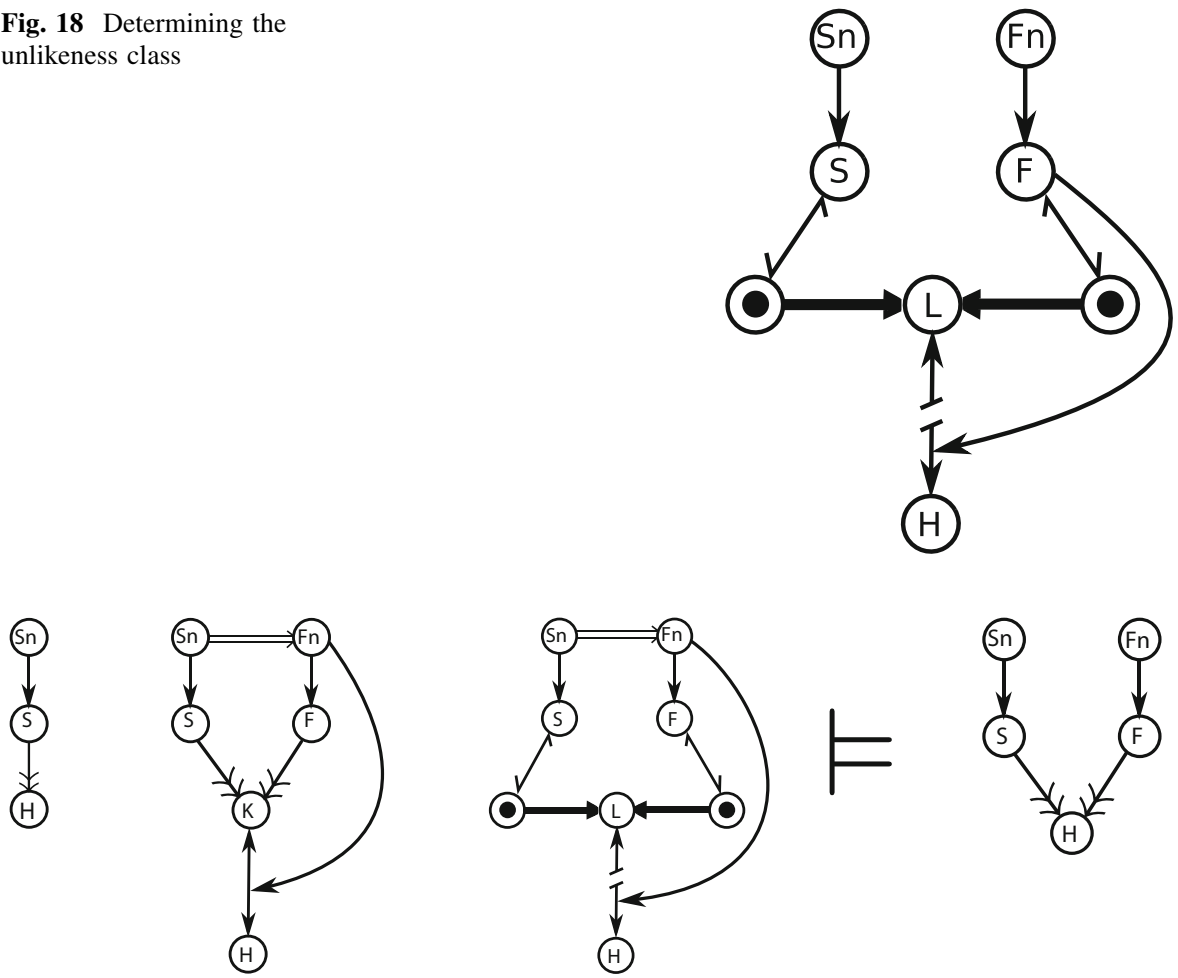

Fig. 19 Applying vyapti with sapakșa and vipakșa

require a second set of nodes, $A \subseteq \mathcal{N}$, disjoint from the bhāva set and representing absential entities. The abstraction would also require two new sets of edges to represent the two new types of edge. We would need to define a new condition with respect to satisfiability, the Abhāva Condition. Similarly to the Bhāva Condition, this must state that each absential node maps to a distinct entity in the universal domain. The Sambhanda Condition would also need to be extended to verify that the new edges do indeed represent relations that exist between entities. Two new inference rules are needed, one which applies anumāna taking vipakșa into account, and one which removes absential nodes. We will omit the extended formalisation for reasons of space and because these details are similar to what has gone before.

\section{Conclusion}

The main content of this paper has been the definition and explanation of anumana diagrams, but we are aware that we also need to justify and motivate the use of diagrammatic reasoning in this domain. Our goal has been to construct logical diagrams that reflect the meaning of Navya-Nyāya, particularly those concepts and relations involved in vyāpti and the anumāna schema. To "reflect the meaning" of 
(1)

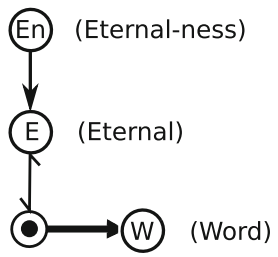

(3)

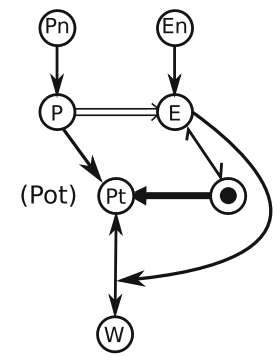

(2)

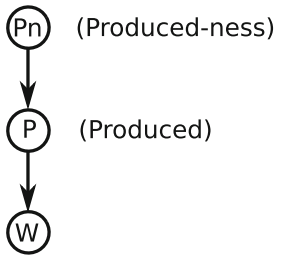

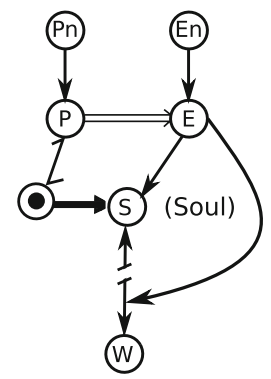

(4)

(5)

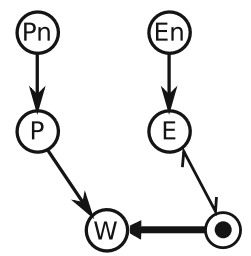

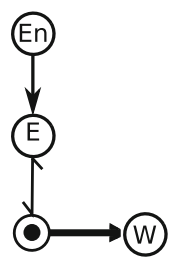

Fig. 20 Negation in sapakșa and vipakșa

those concepts and relations implies more than simply inventing a notation and defining the correspondence between elements of its syntax and the underlying meaning. The potential of diagrammatic reasoning is for this reflection of meaning to expose the most relevant relations at work in a logical expression and enable the viewer to manipulate those relations directly. We have described iconic signs above as signs from which we can "learn more". There are several reasons that we should not expect our diagrams to make their conclusions necessary and apparent in the manner of Euler diagrams: the information conveyed is more complex and is not made up of truth-carrying predicates. However, they are designed with attention focused on choice of notation which is careful to make the best use of earlier efforts and to fit each piece of the notation to its particular semantics. Designing and using iconic diagrams in this way can shed light on the underlying structures of reasoning in a particular system, and on what it means to think diagrammatically. This perspective informed our critical analysis of prior work in the area and fed directly into the style and content of the diagrams.

As well as presenting the full formalisation (i.e. including the vipakșa notation), we plan to extend the notation to cover a larger fragment of Navya-Nyāya. This can be done by adding notation to accommodate ternary relations and concepts such as paryapti, as well as additional rules such as those dealing with negation. However, an important precursor to that extension would be to establish the content of a logically complete notation and set of rules. This would lay the ground work for a principled dialogue between formal representation and the literature of Indian logic.

Acknowledgements Thanks are due to Professors Mihir Chakraborty and Lopamudra Choudhury for the many helpful discussions we had about this work, and for making it possible in the first place by hosting my sabbatical at Jadavpur University. 
Funding Funding was provided by United Kingdom Research Council (Grant Number EP/R043949/1).

\section{Compliance with ethical standards}

Conflict of interest The author states that there is no conflict of interest.

Open Access This article is licensed under a Creative Commons Attribution 4.0 International License, which permits use, sharing, adaptation, distribution and reproduction in any medium or format, as long as you give appropriate credit to the original author(s) and the source, provide a link to the Creative Commons licence, and indicate if changes were made. The images or other third party material in this article are included in the article's Creative Commons licence, unless indicated otherwise in a credit line to the material. If material is not included in the article's Creative Commons licence and your intended use is not permitted by statutory regulation or exceeds the permitted use, you will need to obtain permission directly from the copyright holder. To view a copy of this licence, visit http://creative commons.org/licenses/by/4.0/.

\section{References}

Ambrosio, C. (2014). Iconic representations and representative practices. International Studies in the Philosophy of Science, 28(3), 255-275. https://doi.org/10.1080/02698595.2014.959831.

Burton, J., Chakraborty, M., \& Choudhury, L. (2018). A survey and evaluation of diagrams for NavyaNyāya. In Diagrams 2018: International Conference on Theory and Application of Diagrams (pp. 280-295). Springer.

Cheng, P. H. (2016). What constitutes an effective representation? In M. Jamnik, Y. Uesaka, \& S. Elzer Schwartz (Eds.), Diagrammatic representation and inference. Lecture notes in computer science (Vol. 9781, pp. 17-31). Springer. https://doi.org/10.1007/978-3-319-42333-3_2.

Chi, R. S. Y. (1990). Buddhist formal logic: A study of Dignaga's Hetucakra and K'Uei-Chi's great commentary on the Nyayapravesa (Pt.1). Chennai: Motilal Banarsidass.

Das, R. C. (2006). Navya-Nyayabhasapradipa of Mahesa Candra Nyayaratna. Utkal studies in philosophy. Bhubaneswar: Utkal University Press.

Ganeri, J. (2001a). Indian logic: A reader. New York: Routledge.

Ganeri, J. (2001b). Indian logic and the colonization of reason. In J. Ganeri (Ed.), Indian logic: A reader, Chap. 1 (pp. 1-25). New York: Routledge.

Ganeri, J. (2001). Philosophy in classical India: An introduction and analysis (1st ed.). New York: Routledge.

Gasquet, O., Herzig, A., Said, B., \& Schwarzentruber, F. (2014). Kripke's worlds: An introduction to modal logics via tableaux. Basel: Birkhäuser.

Guha, D. C. (2016). Navya Nyaya system of logic: Basic theories and techniques (3rd ed.). New Delhi: Motilal Banarsidass.

Gurr, C. A. (1999). Effective diagrammatic communication: Syntactic, semantic and pragmatic issues. Journal of Visual Languages \& Computing, 10(4), 317-342. https://doi.org/10.1006/jvlc.1999.0130.

Gurr, C., \& Tourlas, K. (2000). Towards the principled design of software engineering diagrams. In Proceedings of 22nd international conference on software engineering (pp. 509-518). New York: ACM Press.

Hookway, C. (2002). Truth, rationality, and pragmatism: Themes from peirce. Oxford: Clarendon Press. Ingalls, D. (1955). Logic in India. In J. Ganeri (Ed.), Indian logic: A reader, Chap. 6 (pp. 110-117). New York: Routledge.

Matilal, B. K. (1991). Perception. Oxford: Clarendon Press.

Mullick, M. (1976). Implication and entailment in Navya-nyāya logic. Journal of Indian Philosophy, 4(12), 127-134. https://doi.org/10.1007/bf00211110.

Sen, P. K., \& Chatterjee, A. (2010). Navya-nyāya logic. Journal of Indian Council of Philosophical Research, 27, 77-99.

Shin, S. J. (1994). The logical status of diagrams. Cambridge: Cambridge University Press.

Short, T. L. (2009). Peirce's theory of signs (1st ed.). Cambridge: Cambridge University Press. 
Staal, J. F. (1973). The concept of paksa in Indian logic. Journal of Indian Philosophy, 2(2), 156-166. https://doi.org/10.1007/bf00188835.

Wada, T. (2001). The analytical method of Navya-Nyāya. Journal of Indian Philosophy, 29(5-6), 519530 .

Wada, T. (2007). The analytical method of Navya-Nyaya. Gonda indological studies. Leiden: Brill.

Publisher's Note Springer Nature remains neutral with regard to jurisdictional claims in published maps and institutional affiliations. 